\title{
Opisthotonos and midazolam
}

\author{
Roshan Koul, Javed Hashim, Masod Ahmed \\ Department of Child Health, Sultan Qaboos University Hospital, \\ Alkhod 123, Muscat, Oman
}

\section{To The Editor:}

A 3-year-child, weighing $11.4 \mathrm{kgs}$, was admitted in the accident and emergency ward in status epilepticus of more than one hour duration. He was administered diazepam suppository followed by 3 doses of intravenous diazepam. When diazepam failed to control the status epilepticus a loading dose of phenytoin sodium $200 \mathrm{mg}$ (18 mg per $\mathrm{kg}$ ) was given. This too failed to control the status hence, an additional dose of $5 \mathrm{mg}$ per $\mathrm{kg}$ of phenytoin sodium was administered. As the child continued to have seizures, he was shifted to the pediatric intensive care unit and an intravenous bolus of midazolam at $0.1 \mathrm{mg}$ per $\mathrm{kg}$ was given followed by increasing doses by infusion, from $1 \mu \mathrm{g} / \mathrm{kg} /$ minute to $5 \mu \mathrm{g} / \mathrm{kg} /$ minute, which controlled the status. In addition, a dose of mannitol, at $0.5 \mathrm{~g} / \mathrm{kg}$ and dexamethosone $0.15 \mathrm{mg}$ per $\mathrm{kg}$ was given. After the status was controlled abnormal retractions of head and arching of back was observed. This worsened on examining. This posture was noted when the child was in the lateral posture, which reduced when supine. After the seizures control for 4 hours, a tapering of midazolam was started. With $1 \mu \mathrm{g} / \mathrm{kg} / \mathrm{minute}$ there was no opisthotonos. Midazolam was continued for 24 hours and then tapered off. Phenytoin sodium was continued at $5 \mathrm{mg} / \mathrm{kg}, 12$ hourly intravenous for the next 5 days.

Midazolam is a water-soluble benzodiazepine with sedative and anesthetic properties (1). Several side effects are associated with midazolam which include central nervous system effects like hypoxia, apnea, headache, confusion, tremor, vertigo, ataxia and systemic side effects like hypotension, blood disorders and jaundice $(2,3)$. Opisthotonos was recently reported in two children administered midazolam for non-neurological indications (e.g. imaging) (4). Flumazenil given to antagonize side effect of midazolam was reported producing opisthotonos (5). What is the underlying mechanism for the production of opisthotonos with midazolam is not clear. We could postulate it to be related to high dose, as opisthotonos disappeared on reducing the dose. The precise correlation needs further studies.

\section{References}

1. Hanhan UA, Fiallos MR, Orlowski JP. Status epilepticus. Pediatr Clin North Am 2001; 48: 683695.

2. Rey E, Treluyer JM, Pons G. Pharmakokinetic optimization of benzodiazepine therapy for acute seizure. Clin Pharmacokinet 1999; 36: 409-424.

3. Waller D, Renwick A. Principals of Medical Pharmacology. London: Balliere, 1994.

4. Y1lmaz D, Sipahi T. Opisthotonos: a newly recognized side effect of midazolam. J Pediatr Neurol 2003; 2: 49.

5. Watanabe S, Satumae T, Takeshima R, Taguchi N. Opisthotonos after flumazenil administered to antagonize midazolam previously administered to treat developing local anesthetic toxicity. Anesth Analg 1998; 86: 677-678. 